\title{
Why mothers attend playgroup
}

\author{
Bronwyn Harman \\ Andrew Guilfoyle \\ Edith Cowan University
}

\author{
Moira O'Connor \\ Curtin University
}

\begin{abstract}
WHILE IT IS GENERALLY RECOGNISED that early childhood programs play an important role in increasing positive outcomes for children, families and society, there is very little research on the Australian playgroup experience and its role in providing support for mothers and addressing identity issues. The research aimed to fill this gap by asking why mothers attend playgroups and in particular what for them is the role of playgroup in supporting or challenging expectations of motherhood. Methods included one-onone interviews with 11 mothers, aged 26 to 45 years, within the Perth metropolitan area with varied experiences with playgroups and follow-up focus groups with mothers who shared characteristic contexts or situations. The data showed there are three reasons that influence whether mothers will attend playgroup: to develop a sense of belonging; to seek validation as a mother; and, negative experiences of playgroup. This data is discussed in reference to positive and negative experiences, limitations of the study and future research.
\end{abstract}

WHILE PARENTHOOD BRINGS changes for both parents, the changes for mothers are greater than those for fathers (Barkin \& Wisner, 2013). As the twenty-first century progresses, mothering ideology has become more focused on 'intensive mothering' whereby mothers put the needs of their child before their own, and the interests of mother and child merge to one identity (Warr, Mann, Forbes \& Turner, 2013). The dyads in ideologies of motherhood mean that mothers are viewed as 'good' or 'bad' mothers (Hays, 1996; Johnston \& Swanson, 2004), and that they either devote themselves to children or a career (Apple, 2012; Vejar, 2003). In this respect, motherhood is socially constructed.

The focus of extant literature on mothering is given to the transition to motherhood, or issues such as isolation or loss of identity. New motherhood can be characterised by profound change, a strong sense of loss, isolation and fatigue (Vincent, Ball \& Braun, 2010), and the transition to motherhood has been identified as a psychologically vulnerable time for women (Barkin \& Wisner, 2013; Seimyer, Edhborg, Lundh \& Sjogren, 2004). These are important issues that can affect the way mothers mother. However, hardly any research explores the relationship between mothers. This is important research, as it investigates how mothers become socialised into motherhood.
Researchers argue that social support networks are important in providing positive outcomes for both mothers and children. However, such research usually focuses on marginalised groups or perceived social issues, such as low-income mothers (Offer, 2012), mothers with postnatal depression (Leahy-Warren, McCarthy \& Corcoran, 2011), and mothers who are ill (Power, Jackson, Weaver \& Carter, 2011). Conversely, little is known about mainstream support networks, such as playgroup, that do not focus on marginalised groups. Additionally, little is known about the ways mothers interact within these groups.

\section{Playgroups in context}

The definition of a playgroup, according to Playgroup WA (Inc) is 'a group of mothers, and the 0 to 5 year old children for which the former are responsible, interacting in creative play activities' (Playgroup WA [Inc], 2003, p. 1). In Australia there are more than 108000 families attending playgroup each week (Playgroup Australia [Inc], 2007). There are, according to Playgroup WA (Inc) (2013), approximately 500 playgroups in Western Australia, with more than 16500 families as members. This membership consists of more than 22000 children attending one of approximately 1500 playgroup sessions held in Western Australia every week (Playgroup WA [Inc], 2013). While there has been recent research on evaluating playgroups (Dadich, 2008; Jackson, 
2011; Oke, Stanley \& Theobald, 2007; Warr et al., 2013), and research on playgroup in relation to other programs (Greenwald, Siegel, \& Greenwald, 2006; Lamb-Parker, LeBuffe, Powell \& Halpern, 2008; Timber, Volger-Elias \& McGill, 2007), there is, to date, a lack of Australian research into who uses playgroup and, importantly, why (Dadich, 2008; Jackson, 2011).

The aims of playgroups are articulated as encouraging parents, or regular caregivers, and their children to play and have fun together in a safe and stimulating environment, to promote the importance of parents' awareness of their child's developmental needs, and to assist parents to develop support networks (Playgroup WA [Inc], 2003). Playgroup WA (Inc) encourages individual playgroups in Western Australia to uphold these aims (Playgroup WA [Inc], 2004). Playgroup becomes a validating experience for groups of women whose identity has been challenged, coming together to support each other via a vehicle that encompasses their children. Playgroup is a community of women limited or bounded by internal and external demands by finding a space to support each other and shore up identity (Warr et al., 2013).

There is very little research on the Australian playgroup experience and its role in providing support for mothers and identity issues (Dadich, 2008; Jackson, 2011; Warr et al., 2013), but elsewhere it has been shown that emphasis is placed on the importance of coordinated and integrated early childhood services (Mustard, 2006). For instance, Reynolds, Ou and Topitez (2004) investigated the longterm outcomes of educational attainment and delinquency for preschool participants in child-parent centres. The Chicago Longitudinal Study examined outcomes for 1539 minority children of low-income families growing up in high-poverty neighbourhoods. Of those 1539 children, 989 participated in a program that provided educational and family support services to children from three to nine years of age, while 550 children did not participate in the program (Reynolds et al., 2004). The authors found that participants in the program had significantly higher rates of high school completion, and significantly lower rates of juvenile delinquency.

Research has also shown that programs such as playgroup can assist in socially supporting mothers (Deave, Johnson \& Ingram, 2008; Jackson, 2011; Nolan et al., 2012; Warr et al., 2013). For example, Scott, Brady and Glynn (2001) interviewed 243 Australian women to determine the strength of social support that results from new mothers' groups, and found that the majority of new mothers' groups evolve into self-sustaining social support networks that continue 18 months or more after the demise of the formal, structured group meetings. Additionally, Jackson (2006) investigated the experiences of five families from an Australian supported playgroup for refugee families through semi-structured interviews and open-ended questionnaires. One of the major findings of this study was a reduction in social isolation because of friendships developed through the group. In-depth interviews conducted by Oke and colleagues (2007) with 14 parents attending playgroup in the Greater Dandenong (Melbourne) area reported that the support mothers received was an important benefit of the playgroup. Despite these studies, there is no comprehensive evaluation of playgroups in Australia (Dadich, 2008), nor understanding of their role from a mother's perspective.

In summary, it is generally recognised that early childhood programs play an important role in increasing positive outcomes for children and families (Feinberg \& Kan, 2008; Jackson, 2011; McCain, Mustard \& Shanker, 2007; Nolan et al., 2012; Rodrigo, Martin, Maiquez \& Rodriguez, 2007; Shonkoff \& Phillips, 2000; Warr et al., 2013). However, despite playgroup's importance as an early childhood program, there has been very little research to date on who uses playgroup in Australia and why, nor on the playgroup movement itself within an Australian context (Dadich, 2008; Jackson, 2011).

\section{Research design}

Grounded in the theoretical framework of interpretive phenomenology, the qualitative approach of this study explores in detail the understanding and meaning participants attributed to their experiences as they relate to the phenomenon of playgroup (Finlay \& Ballinger, 2006; Smith, Larkin \& Flowers, 2009; Smith \& Osborn, 2008). Interpretative phenomenological analysis highlights experiential claims and concerns of participants, with the aim of offering understanding into how unique individuals in a precise context ascribe meaning to precise events in their lives (Hein \& Austin, 2001; Larkin, Watts \& Clifton, 2006; Smith et al., 2009). This framework allowed for the gathering of rich and meaningful data via semi-structured interviews with participants that allowed for detailed accounts of perceived thoughts, feelings and attitudes of participants (Creswell, 2007). This approach places knowledge within the process of social interchange, highlighting the influence of social context on the meaning one makes of their experience (Gergen, 1985). Interpretive phenomenology draws on a range of theoretical frameworks including phenomenology, hermeneutics and social interactionism. It is phenomenological in that it aims to examine an individual's descriptions, perceptions and explanations of phenomena, such as attending playgroup (Smith et al., 2009; Smith \& Osborn, 2008). Further, interpretive phenomenological analysis is based on hermeneutic principles that are concerned with interpreting or translating meaning and understanding, which emphasises context and initial purpose (Larkin et al., 2006; Patton, 2002). Last, interpretive phenomenology is informed by symbolic interactionism, which ascribes meaning to the processes that occur through social interaction and engagement (Patton, 2002) and the 
understanding that the meaning individuals attribute to phenomena are influenced by interaction with others (Smith \& Osborn, 2008). Guided by these principles of interpretative phenomenology, the present study aims to examine participants' subjective accounts of attending playgroup, in order to understand how they make sense of their experiences and the meaning they ascribe to them.

The research was conducted in two stages. The first stage consisted of one-on-one interviews with 11 mothers, all of whom resided in metropolitan Perth. A letter was sent by Playgroup WA (Inc) staff, blind to the researchers, to 20 Perth playgroups. The letter advised playgroup members of the research, and how to contact the researchers if they chose to participate. The 11 women interviewed were randomly drawn from the seven playgroups that responded. As each one-on-one semi-structured interview was conducted, preliminary thematic analyses were undertaken, which allowed us to develop issues for further exploration and to decide when no new themes were emerging from the data (Shah \& Corley, 2006).

The data collected through the one-on-one interviews were supplemented by two focus groups. Focus groups were used after the one-on-one interviews were conducted and thematically analysed to explore the emergent issue of the role of playgroup in supporting or challenging expectations of motherhood. The first focus group consisted of five mothers who were current playgroup members, who had more than one child from separate births (hereafter referred to as focus group one). These mothers all attended the same playgroup. The second focus group consisted of five mothers who were current playgroup members, who were first-time mothers of children aged between two and three years (hereafter referred to as focus group two). These mothers also attended the same playgroup, but not the same playgroup as the first focus group participants. The participants were recruited again with the assistance of Playgroup WA (Inc). None of the mothers in the focus groups participated in a one-on-one interview.

Both the one-on-one interviews and the focus group interviews were transcribed verbatim as soon as possible after the interviews were completed. Data was analysed using an interpretive framework using Miles and Huberman's (1994) thematic content analysis technique. Several research participants were approached to clarify a point, to expand on a comment made in the previous interview, or invited to comment on such insights. Subthemes and themes were submitted to some participants to verify the truth-value of our interpretation of the text (Berg, 2000). Data interpretations were considered to establish that the themes identified are a true reflection of the data material (Singer, Martin \& Kelner, 1999), as there were no divergent findings.

\section{Results and interpretation}

We argue that three factors influence the mothers interviewed when deciding whether or not to attend playgroup (in order of importance, as identified by the participants): to develop a sense of belonging; to seek validation as a mother; and, negative experiences of playgroup. All of the mothers interviewed indicated that sense of belonging was important in deciding whether to attend playgroup or not, and this was a prevalent theme; seeking validation as a mother was also evident as a major theme; and, negative experiences of playgroup were only reported by a few participants, but were, nevertheless, a determining factor in choosing not to attend playgroup.

\section{Sense of belonging}

Going through similar experiences bonds mothers (Jackson, 2011; Nolan et al., 2012). In accordance with Heneghan, Mercer and DeLeone (2004), who found that mothers gain strength from other mothers, and feel less isolated by attending support groups, our study found that playgroup was sometimes viewed as beneficial for socialisation of both mother and child:

Sometimes when my husband was home from work, I would come to playgroup without the kids. Friday is my playgroup day, it's my time. My boss wanted to change my day off to Monday, and I said no way, Friday is my playgroup day, I'm not changing playgroup. I'd rather quit my job than miss out on playgroup.

I needed the socialisation and so did the boys. I'm the mother of twins, so I understood very early on that I was going to need some sort of support, so it was good for me, but also, I didn't want the boys to get used to being just by themselves and having just each other to play with, though that would be very easy to do.

Friendship from other new mothers can lessen a sense of aloneness and provide support (Feinberg \& Kan, 2008; Nolan et al., 2012; Warr et al., 2013). A perceived lack of support among new mothers can be a stressor, and the ability to share mothering experiences and the stresses of parenting is deemed helpful in reducing the negative effects of such stressors (Heneghan et al., 2004). Mothers in our study viewed playgroup as reassuring them and supporting them in their parenting role, and in providing emotional support that might otherwise be lacking:

Right from the start I realised I was going to need more emotional support than I had. My mother came over for the birth, and the in-laws came over, but it's not the same as having people here all the time, and when you've had a bad night's sleep, being able to call on gran and say hey, you know, so playgroup has been important for me, very, very important for me, and I know there are other people at our playgroup who have a very similar story. 
The importance of informal support was a salient finding in qualitative research of 28 families by Duncan, Bowden and Smith (2006), which found that the opportunity to gossip with both staff and other parents in the three early childhood centres they studied was a key source of support for the families in their study. Similarly, the mothers in our study identified the ability to share information among themselves as an important source of informal support.

\section{Validation as a mother}

The availability of community-based support has been associated with an improvement in the nature of parentchild interactions (Hyun, Lee, Yoo \& Cho, 2002), and helps to establish parenting methods for new mothers (Jackson, 2011; Mize \& Pettit, 2010). Further, reported benefits from informal social support include feelings of community, companionship, normality, mastery and control, and access to emotional and informational assistance (Rodrigo et al., 2007; Solomon, Pinstrang \& Barker, 2001; Warr et al., 2013). Some mothers in our study viewed playgroup as a valuable tool for getting appropriate advice on parenting issues, as it is sometimes the case that parents will not ask 'experts' for advice, especially if the issue seems trivial (Deave et al., 2008; Nolan et al., 2012). Informational support from family members, especially the maternal mother, has been found to be crucial to new mothers (Cronin, 2003), a finding supported by other studies (Jackson, 2011). While family members are viewed as important sources of support, a study of 98 married mothers by Johnston and Swanson (2004) found that mothers seek support from peers, especially those with whom they have a shared context. The mothers in this study shared this view:

[I'm] probably a lot more relaxed about some behaviours than if it was just me without that wider circle of people with kids exactly the same age, I would have thought it was only my children doing it, whereas I know that, okay, all the kids are wetting their pants or whatever behaviour it is, they're all doing it, and you get a bit of an idea on how to deal with it from other people.

Playgroup is always useful for finding out something from the other parents that you don't already know, especially from people who have been coming to playgroup for a long time.

These opinions are reflected in findings from a range of studies (Bailey \& Pain, 2001; Cronin, 2003; Johnston \& Swanson, 2004). New parents will often seek the support of family and peers rather than 'experts'. New parents today have both time and resource pressures, and have therefore become vulnerable to the belief that child rearing is a complex and precipitous business. Their instinctive feelings about their child's needs on every level can be undermined by conflicting advice from both 'experts' and groups of other mothers, which can result in oppression, whereby new parents lack confidence and surrender control to the professionals (Apple, 2012; Daro \& Dodge, 2009).

Australian research indicates that parents are influenced in their parenting styles by contact with other parents at schools, preschools, childcare centres and playgroup (Tucci et al., 2005). This is because such programs provide possible effective means for the extensive distribution of parenting information and support (Tucci et al., 2005). The women in our study reported that they are able to see what they want to be and what they did not want to be as a parent through observation at playgroup:

Well, it's not like you get a book and you have instructions, do you? I think [I learn from] watching other people with kids and talking about their experiences.

That's where sometimes playgroup is, um, quite useful to see, sometimes just to see other children's behaviours and how the parents deal with it. Especially when they are older children, and you think right, next my child's going to be doing that, I look at the way they handled that, do I like the way they've done that and would I handle that differently, and, um. So I find watching other people parent particularly useful, just to work through it in my own mind, um, how best to approach things.

Mothers often take the blame for their children's failures as they take the responsibility for their successes; the child's behaviour is seen to be the liability of the mother (Vejar, 2003). Child rearing is taking place in an increasingly unsupportive framework in modern society, emulating the principle ideology of private parent responsibility (Rullo \& Musatti, 2005).

Parents play a major role in structuring children's social interactions outside the home, but children also influence parents' social worlds by shaping involvement with family, friends and neighbours (Kesselring, de Winter, Horjus, van de Schoot \& van Yperen, 2012). For example, parents seek out other parents at similar stages of child rearing for support (Drentea \& Moren-Cross, 2005; Fieldon \& Gallagher, 2008; Kesselrine et al., 2012). Further, 'mothering is a product of social negotiation between adults as well as between adults and children' (Blackford, 2004, p. 244).

There have been studies of the role of parents, especially mothers, in children's play (Blackford, 2004; Mize \& Pettit, 2010). Blackford (2004) described how, when in groups, women try to corroborate their mothering and their knowledge through telling stories and asking questions, and reveal a need for cultural validation. For example, Blackford (2004) discusses how mothers devise elaborate systems of turn taking, and verbalise them frequently, such as 'only a few more minutes and then let Billy have a turn'; violations in sharing is an area that polarises parents, one 
stating something similar to 'that's not yours' and the other praising sharing behaviour; if a child hurts another, whether accidentally or purposely, the mother quickly apologises to the other mother. Further, parents serve as role models in providing information about appropriate behaviour in a range of settings and in certain activities (Apple, 2012; Mize \& Pettit, 2010). While children generally ignore them, the mothers are discussing and evaluating their values (Blackford, 2004). One mother in our study noted:

Sometimes one of the kids is going through a phase, they're biting, or not sharing, or chucking a wobbly or whatever and, um, the mother gets all embarrassed and, you know, sorry, sorry, but we're like, no, don't worry, it's your kid this week, but next week it might be us.

Mothering, clearly, is a result of social bargaining between adults as well as between adults and children (Blackford, 2004), and this is demonstrated at playgroups.

\section{Negative experiences of playgroup}

Very few women we interviewed found playgroup a negative experience. One mother initially reported:

Well, generally, I find it a bit stressful, as the session leader. And slowly learning myself how to run a session so that everyone helps out, almost equally, rather than the bulk of it falling on to me. This year it's been a lot better because I feel that has been sorted out, and I've got a good group, so I feel as though I can spend time with my children.

However, when we contacted her to ask more details about the stress surrounding playgroup, she qualified the statement by saying that:

I actually find playgroup, generally, a very positive experience, l just get bogged down in the administrative side of things a lot of the time.

Another woman told us that she had decided not to return to playgroup, but she wanted to participate in the research. When we asked why she had decided not to continue with playgroup, she responded that:

I had my third child, and he basically lived in the back of the car and I just thought that it would be better for him to have a sleep on one day a week, and I have a three and a half year old son, he now goes to day care because he missed out on the school intake because he was born [in] July, so he's going to day care to break the umbilical cord, he's getting the social interaction experience through day care without me being there, which is a big crutch for him. So I thought [pause] he's just never enjoyed playgroup, he's never enjoyed it all, so I thought why do it two times a week rather than just the one. And I've been on the committee and I find it hard to hand it over, to let go of things, so it's better for me to just break away completely for a while.
This is not so much a negative experience of playgroup as recognition that family dynamics had changed for this mother, as well as awareness of her personal limitations. This was not the case for another woman, who reported a painful experience indicating lack of support in her early playgroup days:

I didn't go to playgroup for a little while, because it was just too hard. People seemed to look just after their own kids, which is fine if you have just one, but I've got two. The boys were going through an awful stage, where they just wouldn't leave me alone, they wouldn't get off my lap, and they cried the whole time, so I wondered if it was worth it. And when it came to being on roster, when I was making tea and coffee, that was really bad, because l'd put the boys down and they'd just scream and scream, and nobody would help me, or pick them up or anything. And in the end I said look, you're just going to have to do something, you're either going to have to look after the boys or take me off the roster, because it's just not part of my philosophy, letting my kids scream and be distressed while I make teas for all you lot.

These feelings of lack of support on her behalf during her first experience of playgroup are underlined when she explains why she returned to playgroup:

I did go back because the boys still needed that socialisation, I didn't want them to know their cousins and each other and nobody else, so we went back and I found that it was different. And I think the difference has come because some of those mums have had their second babies now, and now they're seeing it, they are seeing how hard it is when you have two to look after, not just one, so they're a lot more supportive now.

Playgroup is clearly not a 'one size fits all' program, and while some mothers might enter and leave at different parenting stages, some find that playgroup does not complement their parenting.

\section{Discussion}

We demonstrated that the women in our study were influenced in their decision to attend playgroup for one of three reasons: to develop a sense of belonging; to seek validation as a mother; and, negative experiences of playgroup. Generally, the women in our study viewed playgroup as a positive experience as it served a number of purposes, such as socialisation of mother and child, provision of support networks, normalisation of the mothering experience and a source of advice from peers. While some of the women in our study viewed playgroup as a negative experience for various reasons, they either chose to leave playgroup, find another playgroup, or reevaluated their participation in playgroup. Overall, however, the general consensus was that playgroup was an invaluable service that supported women in their mothering role. 
A limitation of this study is that it examined motherhood and playgroup in the Perth metropolitan area only; it would be interesting to hear the experiences of mothers in other states or other areas of Western Australia. Future studies could include not only mothers in other states, but also to examine if the issues are also prevalent in rural areas of Australia. It could be suggested, for example, that the concerns of geographical isolation and lack of support are not so dominant in rural areas with smaller populations. Future research could examine playgroup in relation to families that represent cultural or structural diversity, such as migrant groups, same-sex parent families or single parent families.

In summary, this research suggests that mothers choose to attend playgroup, or not, for one of three reasons: to establish and cultivate a sense of belonging; to search for validation as a mother; and, negative experiences of playgroup. It is recognised that playgroup is not always a positive experience for all members, but in those instances, mothers will usually opt out, even if for a short period. If parents perceive themselves as benefiting from programs such as playgroup, then, in order to achieve positive outcomes for families, it would be beneficial for government policy to emanate from the parents' perspective. Services need to become more responsive to the community in order to meet their current needs.

\section{References}

Apple, R. (2012). Seeking perfect motherhood: Women, medicine and libraries. Library Trends, 60(4), 694-705.

Bailey, C., \& Pain, R. (2001). Geographies of infant feeding and access to primary health-care. Health and Social Care in the Community, 9(5), 309-317.

Barkin, J., \& Wisner, K. (2013). The role of maternal self-care in new motherhood. Midwifery, 29, 1050-1055.

Berg, B. (2000). Qualitative research methods for the social sciences (4th edn). Needham Heights: Allyn \& Bacon.

Blackford, H. (2004). Playground panopticism: Ring-around-thechildren, a pocketful of women. Childhood, 11(2), 227-249.

Creswell, J. (2007). Qualitative inquiry and research design: Choosing among five approaches. Thousand Oaks, California: Sage Publications.

Cronin, C. (2003). First-time mothers-identifying their needs, perceptions and experiences. Journal of Clinical Nursing, 12(2), 260-267.

Dadich, A. (2008). Evaluating playgroups: An examination of issues and options. Australian Community Psychologist, 20(1), 95-104.

Daro, D., \& Dodge, K. (2009). Creating community responsibility for child protection: Possibilities and challenges. The Future of Children, 19(2), 67-92.

Deave, T., Johnson, D., \& Ingram, J. (2008). Transition to parenthood: The needs of parents in pregnancy and early parenthood. BMC Pregnancy and Childbirth, 8(30), 1-11.

Drentea, P., \& Moren-Cross, J. (2005). Social capital and social support on the web: The case of an internet mother site. Sociology of Health and IIIness, 27, 920-943.
Duncan, J., Bowden, C., \& Smith, A. (2006). A gossip or a good yack? Reconceptualizing parent support in New Zealand early childhood centre based programmes. International Journal of Early Years Education, 14(1), 1-13.

Feinberg, M., \& Kan, M. (2008). Establishing family foundations: Intervention effects on co-parenting, parent/infant well-being, and parent-child relations. Journal of Family Psychology, 22(2), 253-263.

Fieldon, J., \& Gallagher, L. (2008). Building social capital in firsttime parents through a group-parenting program: A questionnaire survey. International Journal of Nursing Studies, 45, 406-417.

Finlay, L., \& Ballinger, C. (2006) Qualitative research for health professionals: Challenging choices. Chichester: John Wiley Publishers.

Gergen, K. (1985). The social constructionist movement in modern psychology. The American Psychologist, 40(3), 266-275.

Greenwald, L., Siegel, M., \& Greenwald, R. (2006). Kindering Center: A comprehensive early intervention community-based program model. Infants and Young Children, 19(3), 190-202.

Hays, S. (1996). The cultural contradictions of motherhood. New Haven: Yale University Press.

Hein, S., \& Austin, W. (2001). Empirical and hermeneutic approaches to phenomenological research in psychology: A comparison. Psychological Methods, 6(1), 3-17.

Heneghan, A., Mercer, M., \& DeLeone, N. (2004). Will mothers discuss parenting stress and depressive symptoms with their child's pediatrician? Pediatrics, 3(1), 460-467.

Hyun, O., Lee, W., Yoo, A., \& Cho, B. (2002). Social support for two generations of new mothers in selected populations in Korea, Hong Kong, and the United States. Journal of Comparative Family Studies, 33(4), 515-527.

Jackson, D. (2006). Playgroups as protective environments for refugee children at risk of trauma. Australian Journal of Early Childhood, 31(2), 1-5.

Jackson, D. (2011). What's really going on? Parents' views of parent support in three Australian supported playgroups. Australasian Journal of Early Childhood, 36(4), 29-37.

Johnston, D., \& Swanson, D. (2004). Moms hating moms: The Internalization of mother war rhetoric. Sex Roles, 51, 497-509.

Kesselring, M., de Winter, M., Horjus, B., van de Schoot, R., \& van Yperen, T. (2012). Do parents think it takes a village? Parents' attitudes towards nonparental adults' involvement in the upbringing and nurture of children. Journal of Community Psychology, 40(8), 921-937.

Lamb-Parker, F., LeBuffe, P., Powell, G., \& Halpern, E. (2008). A strength-based, systemic mental health approach to support children's social and emotional development. Infants and Young Children, 21(1), 45-55.

Larkin, M., Watts, S., \& Clifton, E. (2006). Giving voice and making sense in interpretative phenomenological analysis. Qualitative Research in Psychology, 3, 102-120.

Leahy-Warren, P., McCarthy, G., \& Corcoran, P. (2011). Firsttime mothers: Social support, maternal parental self-efficacy and postnatal depression. Journal of Clinical Nursing, 21(3/4), 388-397.

McCain, M., Mustard, F., \& Shanker, S. (2007). Early Years study 2: Putting science into action. Toronto: Council for Early Childhood Development.

Miles, M., \& Huberman, A. (1994). Qualitative data analysis: An expanded sourcebook (2nd edn). Thousand Oaks, CA: Sage Publications. 
Mize, J., \& Pettit, G. (2010). The mother-child playgroup as socialisation context: A short-term longitudinal study of motherchild-peer relationship dynamics. Early Child Development and Care, 180(10), 1271-1284.

Mustard, F. (2006). Early child development and experiencebased brain development-the scientific underpinnings of the importance of early child development in a globalised world. Paper presented at the World Bank International Symposium on Early Child Development-A Priority for Sustained Economic Growth and Equity. Retrieved 9 November, 2013, from www.dete.sa.gov. au/wallaradistrict/files/links/Mustard_2006.pdf.

Nolan, M., Mason, V., Snow, S., Messenger, W., Catling, J., \& Upton, P. (2012). Making friends at antenatal classes: A qualitative exploration of friendship across the transition to motherhood. Journal of Perinatal Education, 21(3), 178-185.

Offer, S. (2012). Barriers to social support among low income mothers. The International Journal of Sociology and Social Policy, 32(3/4), 120-133.

Oke, N., Stanley, J., \& Theobald, J. (2007). The inclusive role of playgroups in Greater Dandenong. Fitzroy, Vic: Brotherhood of St Laurence.

Patton, M. (2002). Qualitative research and evaluation methods. Thousand Oaks, CA: Sage Publications.

Playgroup Australia (Inc). (2007). Boom time for babies and playgroups. Retrieved 19 March, 2013, from www. playgroupaustralia.com.au/go/news/boom-time-for-babies-andplaygroups.

Playgroup WA (Inc). (2003). Constitution (as amended). Available from Playgroup WA (Inc), PO Box 61, North Perth, WA 6906.

Playgroup WA (Inc). (2004). Playgroup Charter. Available from Playgroup WA (Inc), PO Box 61, North Perth, WA 6906.

Playgroup WA (Inc). (2013). Annual Report. Available from Playgroup WA (Inc), PO Box 61, North Perth, WA 6906.

Power, T., Jackson, D., Weaver, R., \& Carter, B. (2011). Social support for mothers in illness: A multi-faceted phenomenon. Contemporary Nurse, 40(1), 27-40.

Reynolds, A., Ou, S., \& Topitzes, J. (2004). Paths of effects of early childhood intervention on educational attainment and delinquency: A confirmatory analysis of the Chicago Child-Parent Centers. Child Development, 75(5), 1299-1328.

Rodrigo, M., Martin, J., Maiquez, M., \& Rodriguez, G. (2007). Influence and formal supports and maternal child-rearing practices in at-risk and non at-risk psychosocial contexts. Children and Youth Services Review, 29, 329-347.

Rullo, G., \& Musatti, T. (2005). Mothering young children: Childcare, stress and social life. European Journal of Psychology of Education, 10(2), 107-119.

Scott, D., Brady, S., \& Glynn, P. (2001). New mother groups as a social network intervention: Consumer and maternal and child health nurse perspectives. Australian Journal of Advanced Nursing, 18(4), 23-29.

Seimyer, L., Edhborg, M., Lundh, W., \& Sjogren, B. (2004). In the shadow of maternal depressed mood: Experiences of parenthood during the first year after childbirth. Journal of Psychosomatic Obstetrics and Gynecology, 25, 23-34.

Shah, S., \& Corley, K. (2006). Building better theory by bridging the quantitative-qualitative divide. Journal of Management Studies, 43(8), 1821-1835.

Shonkoff, J., \& Phillips, D. (Eds.) (2000). From neurons to neighborhoods: The science of early childhood development. Washington: National Academy Press.
Singer, P. A., Martin, D. K. \& Kelner, M. (1999). Quality end of life care: Patient's perspectives. The Journal of the American Medical Association, 281(2), 163-168.

Smith, J., \& Osborn, M. (2008). Interpretive phenomenological analysis. In J. A. Smith (Ed.), Qualitative psychology: A practical guide to research methods (pp. 53-80). London: Sage Publications Ltd.

Smith, J., Flowers, P., \& Larkin, M. (2009). Interpretative phenomenological analysis: Theory, method and research. London: Sage Publications Ltd.

Solomon, M., Pinstrang, N., \& Barker, C. (2001). The benefits of mutual support groups for parents of children with disabilities. American Journal of Community Psychology, 29(1), 113-132.

Timber, G., Volger-Elias, D., \& McGill, K. (2007). Strategies for promoting generalization of social communication skills in preschoolers and school-aged children. Language Disorders, 27(2), 167-181.

Tucci, J., Mitchell, J., \& Goddard, C. (2005). The changing face of parenting. Australian Childhood Foundation. Retrieved 7 August, 2013, from www.childhood.org.au.

Vejar, C. (2003). A qualitative approach toward understanding the transition from career to fulltime motherhood. Unpublished doctoral dissertation, Virginia State University.

Vincent, C., Ball, S., \& Braun, A. (2010). Between the estate and the state: Struggling to be a 'good' mother. British Journal of Sociology and Education, 31(2), 123-138.

Warr, D., Mann, R., Forbes, D., \& Turner, C. (2013). Once you've built some trust: Using playgroups to promote children's health and wellbeing for families from migrant backgrounds. Australasian Journal of Early Childhood, 38(1), 41-48. 